\title{
El cuerpo racializado del migrante en La fila india de Antonio Ortuño y Ciudad Berraca de Rodrigo Ramos Bañados*
}

\author{
Tatiana Calderón Le Joliff \\ Universidad Adolfo Ibáñez \\ tatiana.calderon@uai.cl
}

\begin{abstract}
Resumen: Examinar el tratamiento del cuerpo en la literatura de migración en La fila india (2013) de Antonio Ortuño y Ciudad berraca (2018) de Rodrigo Ramos Bañados es el propósito del siguiente trabajo. Usaré el concepto de corpographèse (corpografía) como inscripción del cuerpo como sentido, y sobre todo la proyección en el cuerpo racializado de los disfuncionamientos políticos y sociales de México y Chile. La globalización estimula los flujos migratorios a la vez que desnaturaliza los cuerpos migrantes. La violencia aplicada al cuerpo migrante encuentra un correlato en el rescate del testimonio que opera el texto literario. Apátrida, el sujeto migrante puede recuperar su lugar en la historia y el territorio así como adquirir una doble pertenencia a través de la materialidad de la escritura.
\end{abstract}

Palabras claves: cuerpo, raza, migración, enfermedad, materialidad, testimonio

\begin{abstract}
Examining the treatment of the body in migration literature in La fila india (2013) by Antonio Ortuño and Ciudad berraca (2018) by Rodrigo Ramos Bañados is the purpose of the following paper. I will use the concept of corpographèse (corpography) as an inscription of the body as meaning, and above all the projection on the racialized body of the political and social dysfunctions of Mexico and Chile. Globalization stimulates migratory flows while denaturing migrant bodies. Violence applied to the migrant body finds a correlate in the rescue of the testimony that the literary text operates. Stateless, the migrant subject can recover his or her place in history and territory as well as acquire a double belonging through the materiality of writing.
\end{abstract}

Key Words: body, race, migration, illness, materiality, testimony 


\section{Introducción}

El propósito del presente trabajo es estudiar la representación del cuerpo del migrante a través del concepto de corpografía en dos obras latinoamericanas contemporáneas. Más particularmente me interesaré en el modo en qué la racialización del cuerpo petrifica los sujetos en tránsito o en proceso de asentamiento a la vez que les otorga la posibilidad de materializar una repolitización de la escritura a través del testimonio. La fila india (2013) del escritor mexicano Antonio Ortuño -junto con la novela de Alejandro Hernández, Amarás a Dios por sobre todas las cosas (2013) y de Emiliano Monge, Las tierras arrasadas (2015) - constituye una novela imprescindible sobre la representación de los fenómenos migratorios del siglo XXI, sobre todo el desplazamiento de los centroamericanos hacia Estados Unidos. Las tres obras comparten la misma referencia intertextual al "Infierno" de la Commedia de Dante Alighieri que enmarca el recorrido de los cuerpos migrantes a lo largo de México. La crítica literaria, todavía incipiente sobre la obra de Ortuño, coincide en la unión del mythos y logos, la polifonía, la presencia de arquetipos y retóricas vacías asociadas a la burocracia descrita. Elisa Cairati se interesa en las metáforas del poder, el aspecto testimonial de la obra, la representación de la sociedad mexicana a través de arquetipos y la heterogeneidad narrativa. Idalia Villanueva, en un análisis sustancial, explora la doblez del sujeto, su fractura en un mundo dividido entre víctimas y victimarios así como la animalización y la cosificación de los sujetos migrantes en una perspectiva del biopoder cuyo contrapunto opera en una resistencia que desenmascara el discurso vacío de la burocracia mexicana. Finalmente, Ian Chávez-Flores también trabaja la relación entre mythos y logos pero desde una consideración más general sobre la manera en qué la obra literaria (mythos) puede producir perspectivas de análisis sobre problemas específicos de las ciencias sociales (logos) que, en esta obra, remitiría a la problemática migratoria.

Rodrigo Ramos Bañados, originario de la ciudad desértica de Antofagasta en el norte de Chile, relata el viaje y asentamiento en esta ciudad de Jean Parrada, que migra con su familia desde la selva colombiana, huyendo de las guerrillas y buscando un refugio en, según el coyote que les permite cruzar la frontera, "el país de rotolandia" (30). La dificultad de la travesía, descrita con detalles, con sus pasos fronterizos, los coyotes despiadados de la frontera, los cambios climáticos drásticos, constituye la primera parte de la obra cuyo desarrollo central radica en el asentamiento de la familia Parrada Castillo en Antofalombia, contracción de Antofagasta y Colombia, urbe que acoge una cantidad sustanciosa de inmigrantes colombianos. Esta instalación 
enfrenta Jean a la racialización de su cuerpo, expone su progresiva adaptación y su interacción con la clase media chilena hasta su toma de liderazgo en la batalla de Antofalombia, conflicto entre chilenos y colombianos. Salvo las reseñas periodísticas, la crítica académica sobre esta obra escasea, debido, creo en parte, a su publicación reciente. Rescaté un artículo de Liliana Salinas Herrera en el cual practica un ejercico comparativo entre la obra chilena y El Metro del escritor equatoguineano Donato Ndongo-Bidyogo, deteniéndose específicamente en el desplazamiento de los protagonistas y su relación con el afecto, las transformaciones de su identidad cultural (Homi Bhabha y Stuart Hall) y el imaginario de la migración (Cornelius Castoriadis).

Apoyándome en algunos puntos de análisis trabajados en los textos críticos previos, quisiera enfocarme en la noción de corpographèse o corpografía para estudiar el tratamiento específico del cuerpo migrante. "La corpographèse est une matérialité, et la matérialité fait selon nous partie intégrante du texte/contexte de l'œuvre littéraire ou, plus généralement, langagière" (4), afirman Pierre Zoberman y Marie-Anne Paveau. Este estudio de la materialidad remite a una noción del texto que integra componentes biológicos y físicos y pretende impugnar la ruptura entre el cuerpo y espíritu propuesto por la racionalidad cartesiana (Antonio Damasio). Al trabajar la racialización del cuerpo en la experiencia migrante, me interesaré en la reflexión de Francine Masiello sobre cuerpo y catástrofe en la literatura que, haciendo eco a la noción de corpografía, interroga la noción de experiencia y la materialidad de la escritura en un mundo en crisis.

Para empezar a definir la noción de raza, me gustaría recordar el análisis de Michel Foucault quien, primero trabaja la idea de raza como una consecuencia del pasaje del Estado soberano que desarrolla un discurso unitario a un Estado que deja emerger la lucha de las razas dividiendo en un modo binario el cuerpo social, y exponiendo una contra-historia, con un discurso revolucionario que implementa el continuum de la guerra en la paz (43). Esta contra-historia instauraría un racismo interno abocado a la purificación y promoviendo la normalización y los conservatismos sociales. Luego, ocurre otra transformación de la noción de raza en una contrahistoria que erradica la perspectiva histórica instalándose en un discurso biológico-médico. Surge entonces “[1]e racisme ..., littéralement, le discours révolutionnaire, mais à l'envers" (56). Este Estado racista modifica la idea de profecía prometida en el discurso revolucionario e inscribe en sus mecanismos el surgimiento del biopoder (168) en las sociedades modernas, una manera de decidir sobre la vida o muerte de los sujetos y de fraccionar el ámbito de lo biológico para construir grupos diferenciados. Este relato guerrero asegura la imposibilidad de una paz sin violencia (169). Los migrantes que transitan o se asientan en La fila india o Ciudad berraca, son 
cuerpos racializados que sufren el tratamiento de cuerpos también racializados por el proceso colonial.

En Necropolítica, el filósofo Achille Mbembé retoma la noción de biopoder de Foucault y la relaciona con dos otros conceptos en el mundo contemporáneo : el estado de excepción y el estado de sitio (21) que fundamentan el derecho a matar. El arquetipo del poder que reúne las propiedades del Estado racista, mortífero y suicida es el Estado nazi. El historiador Maurice Olender recuerda la connotación positiva del término raza, antes de convertirse en una palabra de repudio, cuando se relacionaba con la legitimidad (transmisión, la familia, la posteridad y los herederos) y con el sistema, procedimiento y por lo tanto la ratio latina que produce la aptitud a pensar, ordenar, clasificar. Esta voluntad de razonar corresponde al inventorio de las ciencias del siglo XIX y su nuevo orden antropológico (15-16). Esta herramienta taxinómica, imperante en el mundo colonizado, tiende a deshistorizar los relatos y proyectar en el cuerpo "La fatalité de la race” (28). Mabel Moraña, al considerar la aplicación de la biopolítica en América Latina y la racialización del Estado, no puede "referirse a la historia latinoamericana sin pasar por las mutilaciones del cuerpo social, su deterioro, su desaparición real o imaginada” (8).

Al escoger La fila india como título de su obra, Ortuño caracteriza a la "raza" de los burócratas cuya violencia contradictoria representa al Estado racista. El origen de la expresión remite a una estrategia de los indios americanos para dejar una sola huella de su paso, también a la conformación espacial de los senderos en el paisaje norteamericano, así como a la jerarquía de los integrantes en una comunidad. Ciudad berraca de Ramos Bañados remite más bien a la animalización que ocurre en el espacio urbano fragmentado en facciones raciales, en estereotipos que engendran una violencia absoluta e instinctiva. Los dos títulos indican dos realidades migratorias en países que han sido colonias antes de convertirse en países de acogida o de tránsito para migrantes con los cuales no comparten una historia colonial como es el caso de muchos países europeos.

Las dos obras enlazan el cuerpo racializado del migrante con la política en una relación guerrera. La masacre identifica los espacios fronterizos de Santa Rita y de Antofalombia. "[L]a inmaterialidad de las personas en tránsito" (Ramos Bañados 22) contradice la petrificación de los cuerpos racializados de los migrantes en las dos obras. Esta paradoja recorre el texto literario, que trabaja con la ausencia del cuerpo y convierte su inscripción en la escritura en una materialidad del testimonio. Para observar esta dinámica de vaíven, estudiaré primero la representación de la migración como una enfermedad voluble y reveladora de las crisis y los estados de guerras más o 
menos latentes de los países de recepción. Luego, me interesaré en la dimensión estática y a la vez transgresora del esterotipo de la raza en los cuerpos migrantes. Finalmente, analizaré como la institucionalización de la violencia da lugar, a través de la materialidad de la escritura, a corpografías que dan la posibilidad de pensar la dimensión testimonial de las obras.

\section{Migración como contagio : síntomas de un cuerpo social enfermo}

\section{1) Urbes fronterizas : límites internos}

Las dos obras sitúan el drama migratorio en una urbe que consta de todas las características de lo fronterizo. Santa Rita en La fila india es una ciudad a medio hacer, aislada, desordenada, anárquica, olvidada del resto del mundo. Antofagasta, en Chile, es una ciudad encajada entre el mar y la montaña, cerca del desierto, de las minas del norte y de las fronteras con Argentina y Bolivia, a unos $1300 \mathrm{~km}$ de la capital. Lugares periféricos, aislados, se convierten en espacios carcelarios para los personajes.

Ángel Rama y José Luis Romero reflexionaron sobre la conformación de la ciudad letrada en América Latina, esta ciudad escindida, transculturada, marcada por la colonia y su imaginario abstracto. Esta ciudad importada de España cuyo diseño en damero, ordena de manera ficticia el paisaje que, de hecho, se desmorona de alguna manera por esta imposición forzada. Esta ciudad letrada como un espacio atiborrado de signos, como un conjunto de lenguajes esparcidos (Rama), instaura la colonialidad del poder que pervive aún después de la emancipación de los países latinoamericanos fundándose en la clasificación social y racial (Quijano 285). La ideología importada, un tajo en la identidad mestiza de los habitantes cuyo trauma original no logra sanarse, importa también el odio de raza.

Los cuerpos migrantes que se desplazan o se instalan en México y Chile sufren así una doble subalternidad. El tránsito de los centroamericanos hacia el norte, hacia México y de los colombianos hacia el sur, Chile refuerza la racialización impuesta por Europa y el blanqueamiento de los países marcados por el mestizaje.

Al analizar la obra de Ortuño, Villanueva recalca el carácter carcelario del pueblo de Santa Rita, el panoptismo que impera en medio de una organización caótica. Aún así, este espacio de tránsito es mejor que el lugar de origen. El único escape para los sobrevivientes es buscar un espacio de una alteridad absoluta, una heterotopía según Foucault. Para Irma la protagonista y su 
hija, así como para la Flaca esclavizada por el padre de Irma, la hija, Estados Unidos "se convierte en una heterotopía compensatoria que permite escapar el horror y el infierno, del desgobierno" (Villanueva 99). Al apuntar al desgobierno de México, se subraya la idea de lo fronterizo y de la ingobernabilidad frente a los flujos migratorios.

La ciudad de Antofagasta se convierte en el sueño chileno de algunos migrantes, este lugar de asentamiento y se transforma en Antofalombia, una ciudad compartimentada a la frontera de un mundo, donde colindan barrios periféricos y de clase media. Para llegar a este espacio, los migrantes tienen que sortear el frío, la alta planicie andina, y cruzar esta frontera "de inmigrantes y locos" (Ramos Bañados 20). Esta ciudad híbrida y fronteriza vive las gesticulaciones de una sociedad mestiza pero hermética al extranjero, proyectando una racismo importado. Las dos ciudades fronterizas protagonizan la llegada de los migrantes que tratan como una plaga, una enfermedad contagiosa.

\section{2) De la epidemia burocrática a la epidemia migratoria}

Olender recuerda la importancia de la creencia de la contaminación como una característica inmutable que afectaría la relación construida entre las razas (19). La idea de raza remite a una naturaleza sin tiempo, ni cambios : sin historia. En la obra de Ortuño aparecen dos plagas en México : los migrantes y la burocracia. El ex-marido de la negra Irma conforma la voz del odio racial en la obra y proyecta esta representación del migrante como un animal apestado : “A veces lo acompañan jaurías de niños sucios, de ojos vacíos, pero generalmente son hombres solos o parejas o grupos de mujeres, prietos todos, garras en vez de manos y con ellas, costrosas en cada dedo y cada tendón, tocan mi puerta" (114). Aparece la idea de animalización con las garras, la deshumanización con la pérdida de la mirada, el color de la piel así como la representación de la enfermedad con las costras que recubren su cuerpo. El cuerpo del migrante deviene una caricatura del miedo al migrante. La otra ocurrencia de esta epidemia es cuando Irma se destierra a Estados Unidos para escapar de las represalias de la burocracia/mafia de México: "Nos acusaban de ser una plaga, pero olvidaban que nuestra víctima principal éramos nosotros. Éramos una epidemia, sí, pero autocontrolable" (225). Se observa la lucidez de la ex-burócrata, acechada por su propio gremio corrupto, acerca de la ambivalencia de su rol en México, a la vez parte del poder y empática con los migrantes. Ahora, ella es la migrante y se da cuenta de su propia subalternidad y de la situación de su país que busca controlar sus propios brotes enfermizos, victimas y 
victimarios, sin mucho éxito. Esta idea de doblez ligada a una deconstrucción en el sentido derridiano, es decir de inversión de la jerarquía, aparece en el trabajo de Villanueva (96).

En Ciudad berraca, está también muy presente el campo léxico del contagio relacionado con la migración:

Pronto, en la noche, y a veces frente a la mirada indiferente de los madrugadores inmigrantes, los rayados xenófobos resurgían como un terco sarpullido ante los rostros a los que solo podía ahuyentar una ráfaga de balas en la fogosa vegetación del valle, del famoso Valle del Cauca. (12)

Aquí la enfermedad está en los signos racistas que plagan las murallas de la ciudad y que ya no espantan a los migrantes que han pasado cerca de la muerte. También aquí la enfermedad es doble, del lado de los que rechazan al otro y del lado de los migrantes pero siempre está en la proyección sobre los migrantes. En la obra aparece con el mismo campo léxico el miedo a las enfermedades sexuales que vehicularían los migrantes según las autoridades políticas, junto con los trastornos ligados al tráfico de droga que “dejaba a los faloperos chilenos con catarro y los ojos picando, con gesticulaciones obscenas" (15). Los responsables políticos y los medios de comunicación participan de la campaña infecciosa de los migrantes y crean la enfermedad en los "puros" chilenos: "Sin embargo, la escena de los extranjeros fabricando hueveo y golpeándose unos a otros asomaba a diario en los medios de comunicación, y eso hacía brotar la urticaria en los antofagastinos más conservadores" (16). El cuerpo del otro migrante y sus acciones contaminan a la sociedad chilena que cierra su entendimiento y su raciocinio para elaborar un cerco sanitario alrededor del miedo a la mezcla de razas. La paradoja es irónica para un país que no reconoce su origen mestizo. Tal como lo describe Foucault, se pasó de una guerra de razas a un racismo de Estado para perpetuar las relaciones de poder. Estos cuerpos enfermos que corresponden a las dos sociedades descritas, la mexicana y la chilena, luchan contra sus propios síntomas, encarnados por los cuerpos migrantes prolongando la guerra en la paz.

\section{3) Guerras verticales y máquinas de guerra}

Mbembé retoma la definición de Foucault de "lo político como relación guerrera por excelencia” (25) y agrega una reflexión sobre la esclavitud como expresión de la biopolítica (31). Se puede hacer un símil entre la condición de migrante y esclavo en las neocolonias de México y Chile. Cuando Mbembé habla del esclavo, se refiere a los que trabajan en las plantaciones de las 
colonias y que han sufrido una triple pérdida (hogar, derecho sobre su cuerpo y estatus político) que no tienen libertad y cuyo escape es la muerte. La humanidad del esclavo en ese contexto surge como una sombra personificada (31). El migrante, que muchas veces, termina siendo literalmente un esclavo, experimenta las mismas pérdidas. El tránsito lo destierra, su cuerpo es instrumentalizado y no tiene estatus político en los espacios en qué se inserta, al menos a su llegada. Este cuerpo migrante/esclavo se aparenta a las máquinas de guerra (Yein en La fila india, Jean en Ciudad berraca) que describe Mbembé al hablar de la ocupación colonial palestina cuyo funcionamiento es emblemático del necropoder.

El filósofo primero subraya la fragmentariedad de la ocupación urbana en esta colonia, característica del mundo contemporáneo, mostrando enclaves periféricos y gated communities (49). La voluntad de no cruzar las vías y así evitar cualquier contacto entre los palestinos y israelitas produce un paisaje urbano encabalgado que desencadena el incremento vertical de la violencia. Los espacios de guerra ya no están en el plano horizontal de la superficie sino que tanto lo construido en lo subterráneo como en el espacio aéreo constituyen zonas de conflictos (50). En estas guerras donde el espacio es inestable, las máquinas de guerras deben ser lábiles y metamórficas. En el biopoder, se ejerce un control sobre los cuerpos, en el necropoder las "nuevas tecnologías de destrucción no se ven tan afectadas por el hecho de inscribir los cuerpos en el interior de aparatos disciplinarios como por inscribirlos, llegado el momento, en el orden de la economía máxima, representado hoy por la "masacre"” (62). La noción de masacre es fundamental para abordar la obra de Ortuño y en menor medida la de Ramos Bañados. La pura destrucción acompañada por exceso y escándalo (Mbembé 72) que luego se difumina prontamente, se puede ver primero en el contexto que rodea el asesinato de la asistente social Gloria reemplazada luego por la protagonista Irma : "Quién castigaría una simple muerte en medio de una masacre" (17). La banalización de la muerte violenta, la aniquilación de los migrantes en su supuesto refugio en $L a$ fila india, y el incendio provocado para matar a colombianos en Ciudad berraca desmaterializan su cuerpo prescindible en la economía máxima. 


\section{Cuerpo del migrante racializado : inmovilidad nomádica}

\section{1) Los estereotipos de la raza : mythos y logos}

Varias paradojas emanan acerca de la construcción de la raza en el mundo occidental y su extensión al mundo colonial y postcolonial. Olender evoca otra contradicción al agregar la noción de mito a la relación entre raza y erudición. La noción de raza ha sido fundamentada por los científicos más reconocidos del siglo XIX, que se convierten así en administradores coloniales, especialistas de la "raza". El mito aparece junto con la erudición para propulsar, entre otras cosas "l'imaginaire politique des généalogies nationales"4 (21). Los rasgos específicos del pensamiento de la "raza" se perpetuan en el siglo XXI y sobre todo en la proyección sobre los migrantes : lo irreductible ; lo indeleble ; lo inamovible, la constante ; lo substancial ; lo esencial (25-26).

El esencialismo apunta a la petrificación del otro en una mirada anhistórica (35). Frantz Fanon también subraya este proceso del colonialismo en Les damnés de la terre, condenando la llegada del colono que petrifica los individuos autóctonos y acarrea la muerte social : "Pour le colonisé, la vie ne peut surgir que du cadavre en décomposition du colon” (95). La petrificación también emerge como sistema de control de las poblaciones rurales que no pueden desarrollarse de manera natural y se quedan en un especie de atemporalidad, un sistema inmutable, empujado por el aparato colonial (111).

En Peau noire, masques blancs, Fanon aborda otro problema ligado al tema de la raza que remite al color mismo de la piel. La jerarquía de los colores, muy presente en el mundo colonial, se perpetúa en la percepción de los migrantes al llegar a su destino. La supuesta inferioridad del hombre negro frente al hombre blanco ocurre cuando se desplaza. Cuando se ve en la mirada del otro, la construcción de su cuerpo se modifica : "Tout autour du corps règne une atmosphère d'incertitude certaine" (119). Este proceso se relaciona con la epidermización, la relación a través de los cuerpos y más específicamente de la piel. El hombre negro, al desplazarse, se edifica entonces a través del espejo de la mirada blanca.

El intelectual Aníbal Quijano ratifica esta visión desde América Latina donde la racialización ha subordinado el cuerpo, decisivo en las relaciones de poder (318), a una jerarquía importada, una colonialidad perpetuada. La clasificación social o racial prevalece en las dos obras estudiadas. Los mexicanos o los chilenos clasifican a los migrantes según estereotipos o clichés pertenecientes a esta jerarquía de los colores. En La fila india, el Biempensante, padre de Irma, 
establece una distinción, supuestamente argumentada, entre hondureños (negros), panameños (negros pero educados), mexicanos (más blancos), argentinos (más blancos), gringos, españoles a la vez que reniega de su racismo :

No, la verdad, no es racial. También hay cuestiones culturales, de educación, no es lo mismo. Unos sacan las cintas métricas. ... Total, somos distintos. Mírame. Dime si parezco. Dime si parezco. Pero los racistas son los gringos, los españoles. ¿Has notado que los españoles son racistas con todos los putos latinoamericanos menos con los argentinos y los mexicanos? (52)

El Biempensante está obsesionado con la mismidad, y saca a relucir los instrumentos de medición aludiendo a la clasificación por órganos. Luego se desentiende del racismo atribuyéndolo a los europeos que sí saben hacer la diferencia y establecer una jerarquía digna entre las buenas razas y las malas. La negación del racismo hace parte del aparato argumentativo del Biempensante cuya hipocresía radica en su propia dificultad para definirse. También subraya la obsesión de los mexicanos por los territorios perdidos de Texas y por la clasificación que el otro, más blanco, también ejerce hacía él: "Porque un gringo típico nos piensa monos y nos clasifica según criterios zoológicos" (147). Se percibe el espacio intersticial del mexicano, el in-between (Bhabha) incómodo que empuja a reforzar una jerarquía que lo petrifica como individuo.

En Ciudad Berraca, Jean observa al nuevo país al que llegó, sin mayores prejuicios, y se da cuenta que "Chile era un país de clasificación de personas y debían habituarse a ello" (38). Sus vecinos en la población, los Lulas, son delincuentes con los mismos prejuicios que la gran mayoría de la sociedad chilena presente en Antofagasta. Para reírse, le regalan, de manera infantil, tarros de chocolate en polvo Milo porque es negro de piel lo que provoca su propia reflexión : "Tenía diecisiete años y era un negro extranjero, y dadas estas características, estaba en el último vagón del tren debajo de los perritos finos y falderos que paseaban por los alrededores del condominio" (65). La bestialización del cuerpo migrante es una constante en las obras y justifica su destrucción.

Los clichés sexuales también se exponen en las obras y ejemplifican lo que Olender señala sobre lazos estructurales e históricos en las representaciones que asocian raza y sexo (18). De nuevo se fabrica una petrificación y epidermización del cuerpo que conlleva una mirada narcisista destructora. El espejo que refleja los rasgos racializados produce una apropiación perversa por el mismo cuerpo migrante. En el texto de Ramos Bañados, Jean se ve como "un negro bello, dotado con una respetable anaconda" (83), para darse ánimo y acercarse a una adolescente pecosa que lo 
atrae. Los chilenos, por su parte, proyectan sus propias fantasías corporales: “otros les sonsacaban el mito, o eso querían creer, del pene enorme" (87) y reifican los atributos corporales de las colombianas comparándolas con autos. En La fila india, más bien pervive el sexo como violación centrado en las mujeres.

Otras características de la petrificación son los clichés de los olores corporales y los bailes. El Biempensante no quiere decirlo pero, en su corriente de la conciencia, termina expresándolo "Que huelen mal" (51). Mientras que los colombianos de Ciudad berraca, son descritos como cuerpos libres y sensuales que bailan todo el tiempo: “armaban allí pequeñas rumbas de un híbrido entre cumbia, salsa y reguetón" (11). Los migrantes en las obras están encerrados en una sala de espejos donde un narcisismo torcido impera, provocando tanto en los habitantes del lugar de destino como en los desplazados una imagen petrificada, falseada e importada de su identidad. El movimiento de los migrantes no impide el enmascaramiento.

\section{2) Las máscaras migrantes : arma, arquetipo, blanqueamiento}

Uno de los dos epígrafes que escoge Ortuño refiere a la obra de Bertolt Brecht : "Todo esto no es más que teatro. Simples tablas y lunas de cartón. Pero los mataderos que se encuentran detrás son reales" (11). La máscara del teatro que representa la crudeza del mundo pero no la supera me recuerda la reflexión de Mbembé sobre la trampa del cuerpo. Cuando analiza las guerras contemporáneas y el uso del cuerpo como arma en los actos terroristas, destaca la máscara del cuerpo : "El candidato a mártir transforma su cuerpo en máscara, escondiendo el arma a punto de ser activada" (67). Nadie puede darse cuenta de lo que está ocurriendo, todo parece normal. La guerra penetra en la banalidad de la cotidianidad, a cada instante puede matar al cuerpo ajeno, sin avisos, sin protocolos, sin manera de resguardarse, de ser valiente o cobarde. La migrante Yein de La fila india encarna este cuerpo máscara que se convierte en arma y explota en el momento menos pensado para sus víctimas.

La máscara también se puede pensar a través de los arquetipos que aparecen en las obras, tanto del punto de vista de la petrificación del cuerpo migrante pero también de las sociedades descritas. Cairati subraya la recurrencia de los arquetipos de la sociedad mexicana : la asistente social Irma, el burócrata/asesino Vidal, el Biempensante (271). Villanueva ve en el arquetipo de la supremacía que encarna Vidal la imagen del panóptico (88). Sin embargo, estos arquetipos, se fragmentan, se disuelven : “... el catedrático, en lugar de ser fuente de sabiduría basada en la razón, se convierte en un salvaje que viola a una mujer" (96). En la obra de Ramos Bañados, todos 
los habitantes de la ciudad, salvo algunas excepciones, parecen encarnar un arquetipo negativo de la clase media chilena: aspiracional, resentida, pronta al odio.

La aspiración a ser otro y esconder su origen bajo la máscara del blanqueamiento está descrito en las obras de Fanon que propone el término de sociogenia que remite a la "doble conciencia" de ser negro y reconocerse a través de la mirada del otro. En el pueblo de Santa Rita, los habitantes desprecian a los migrantes centroamericanos y ostentan una máscara blanca: “o han visto a los retoños de los santarritenses con los pelos teñidos con shampoo de manzanilla? Es encantadora la manzanilla. La delación perfecta de la imbecilidad de un padre” (146). El blanqueamiento también aparece en Ciudad berraca, cuando Jean se imagina a Chile a través de la imagen que el propio país entrega a nivel internacional : "también lo imaginaba como un témpano de hielo con el agua muy helada y sin grones, y volvió a imaginar la idea de refugiarse en un tanque si alguien lo discriminaba por su color" (23). Esta imagen alude a la famosa exposición de Sevilla en 1992, cuando Chile decidió mandar como representación de su identidad, de su modernidad, un témpano de hielo. Numerosos escritores y críticos como Marco Antonio de la Parra, en La mala memoria: Historia personal de Chile contemporáneo (1998), así como Ariel Dorfman en La nana y el iceberg (1999) recalcaron con ironía este gesto chileno de aparentar, de limpiar su imagen oscurecida por la dictadura, con este hielo blanco y frío. El blanqueamiento "volverse blanco o desaparecer" (Fanon) remite también al teórico Homi Bhabha quien habla de camuflaje (150) como técnica de guerra y evidencia esta relación guerrera que sigue manifestándose en la cotidianidad de las sociedades.

\section{3) Cuerpos bultos y cuerpos órganos}

Los cuerpos migrantes representados en las obras son racializados por las sociedades que los acogen, reducidos a una metáfora animal, rechazados en una naturaleza sin historia o "dissous au sein du groupe auquel on l'assigne" (Olender 36). Mbembé, al hablar de los sujetos en las nuevas guerras, habla de "corporalidades vacías, desprovistas de sentido, formas extrañas sumergidas en el estupor" (64). La guerra contra el narcotráfico que ocurre en México y que contamina todos los aspectos de la sociedad también afecta a los migrantes que se convierten en máquinas de guerras, en esclavos del sistema económico neoliberal. Sus cuerpos son despedazados, fragmentados, mutilados en el tránsito que los conduce, si sobreviven, a la tierra prometida de Estados Unidos. La disolución del cuerpo muestra la letalidad de los grupos armados 
que muchas veces tienen la máscara del Estado (Mbembé 64) y busca mantener el terror en sus ciudadanos.

Los cuerpos desechables se pueden dividir en los cuerpos bultos y los cuerpos órganos. Los cuerpos bultos remiten a la desaparición ontológica del otro, su reificación y esclavitud. Los cuerpos órganos sufren una desmembración simbólica y muchas veces literal, actuando de manera metonímica. La reducción del significado al órgano resalta el síntoma de una enfermedad y también muestra, en algunos casos, una reacción a la crisis.

La esclavitud sexual de los migrantes muestra este cuerpo bulto que puede ser transportado de un lugar a otro sin miramientos ni humanidad. En el paso de los migrantes por México, la violación parece un derecho por pasar, un canje, que no provoca reacción ni siquiera en la propia pareja : "A él, que ahora mira por la ventana y suspira, le exigieron a la mujer el segundo día. Se la llevaron a un cuarto aparte, se la cogieron. Era eso o que los bajaran a tiros. No volvieron a abrir la boca. Ni él ni la esposa" (22). Las máquinas de guerra enmudecen a los cuerpos bultos, no tienen derecho a hablar, existir, exigir, a nada en realidad. Yein recibe el trato del cuerpo bulto pero al sobrevivir, termina rebelándose y constituyéndose en un arma. El colombiano Jean también es usado como un objeto sexual de manera menos traumática que Yein : "Parecer el esclavo sexual podía ser el costo de la supervivencia, pensó Jean, quizás Farandato sí lo pensaba, pero a final de cuentas al joven le satisfacía que una persona como el profesor recuperara su alegría después de su pérdida" (120). Por eso su sobrevivencia no se asocia con el martirio y la muerte, más bien como un triunfo sobre petrificación. En filigrana, en la obra, aparece también la mención a los cuerpos desaparecidos durante la dictadura de Pinochet y escondidos en algún lugar del desierto lo que enlaza la crisis migratoria a la crisis societal.

El cuerpo órgano representado en las obras, refleja la crisis de la sociedad contemporánea que Masiello cuestiona a través del sensorio humano (493). El ojo es un órgano esencial para representar las visiones de los autores. En particular en Ciudad berraca, la mirada expresa la ansiedad de la sociedad chilena contemporánea en una escopofilia enviciada (Fanon). Son miradas agudas, intrusas: "Y por supuesto que las miradas eran punzantes si estos inmigrantes querían transformar esto en Antofalombia" (10). Jean se da cuenta del vacío que aparece en las miradas de los habitantes de los campamentos periféricos que integran chilenos inmigrantes y migrantes de otros países. Estas miradas, no obstante, no difieren de "las miradas de ansiedad, de desesperación, de la clase media; la de los vecinos de las casas con piscina que se peleaban el pan caliente y las paltas blandas de la panadería San Juan” (53). 
En La fila india, las manos y las piernas son órganos desarticulados en cuerpos aniquilados o enloquecidos: "Una mano salió de la sombra. Abierta, lastimosa" (15). La segunda página de la novela se enfoca en el elemento metonímico de la mano destacada del cadáver como un elemento del cuerpo recortado en la luz. En la víspera de la masacre, el cuerpo órgano es el único que muestra la crisis, la locura de la aniquilación: "Su pierna derecha golpea el suelo, se mueve sola, como si fuera a escaparse sin esperar a la compañera, la cadera o los pies” (21). El cuerpo órgano del victimario es también él de la víctima en este país de paso bajo el régimen de la colonialidad.

\section{La crítica de la razón burocrática : Cuerpos migrantes en "devenir"}

\section{1) La burocracia y la masacre}

La "síntesis entre la masacre y la burocracia, esa encarnación de la racionalidad occidental" (Mbembé 36), cuyo ejemplo más macabro es el genocidio judío durante la Segunda Guerra Mundial, constituye el argumento central de La fila india. La empresa funeraria está a cargo de la propia Conami, nombre ficticio para representar a la institución encargada de los procesos migratorios en México, cuyas cabezas o autoridades lucran con la muerte. La Conami, frente a la masacre reiterada de los migrantes centroamericanos a lo largo de su territorio, solo es capaz de producir la misma retórica vacía en un boletín cuyas palabras no varían casi en una estructura circular del tiempo ligada al mito del eterno retorno (Villanueva 87). Esta institución burocrática compone la fila india, esta jerarquía sin sentido y sin propósito :

Y todo, la sumisión, la abyección, el desastre, lo conoces, pero a que no sabías o no habías notado que los funcionarios avanzan siempre en fila india, una fila india escalonada entre el punto a y b y luego de regreso, y ejecutan movimientos que nadie en su mejor juicio se interesaría en probar: caminar tomados del brazo; saludar a la obligada multitud con el bíceps a medias flexionado y la palma volteada hacia el rostro, como para mirarse en un espejo; palparse los antebrazos con manos amorosas, sonriendo, a la vez, al vacío. (64)

La raza burócrata no sabe mirar al otro, solo al espejo, de manera narcisista. Es una epidemia que deshumaniza al migrante a la vez que se deshumaniza: "El café pululaba de raza burócrata" (151). La banalidad del mal acuñada por Hannah Arendt asoma en estos rostros enmascarados, en estos rituales sin sensorio, sin significación, en una banalización tal de la violencia que hasta la abyección parece natural. 
Las instituciones en Ciudad berraca aparecen como telón de fondo. No parece existir tan explícitamente, al menos, la automatización burócrata de la violencia. Aparecen sin embargo tres instituciones, el Registro Civil, el Servicio médico legal, y la Asistencia social. La primera institución emerge en el discurso del norteamericano marginal que vive en la basura de Antofalombia. Con extrema lucidez, muestra la ridiculez del sistema de clase chileno, y su ansia por el blanqueamiento y la clasificación:

Para estos chilenos que se creen lo mejor de Sudamérica, siempre seré un extranjero como todos los gringos rubios de los Estados Unidos de América y podré conseguir cosas solo con mi nacionalidad, a pesar de que viva en la basura; en cambio a ustedes siempre les llamarán los inmigrantes negritos de Colombia, pasarán generaciones y generaciones siendo los inmigrantes negritos de Colombia. (111)

Con sarcasmo, destroza en algunas frases la arrogancia de un país que no termina de conocerse y la escala racial a la cual están sometidos los cuerpos negros de Colombia. A pesar de poder conseguir papeles nunca se integrarán. En el Servicio Médico Legal, van las madres a reconocer "a alguno de los seis colombianos achurruscados" (132), después del incendio provocado al final de la batalla de Antofalombia. La última institución está representada por la asistente social que participa de la violencia hacia a los inmigrantes pero no procesa todavía la ira que la incomoda. Presa del miedo "al que dirán", no quiere aparecer "como cómplice de esa historia de odio racial" (143) pero lo identifica. La institucionalización de la violencia racial está integrada en la obra de Ortuño y está en proceso de asimilación en Ciudad berraca, como una sociedad que todavía no digiere su propia violencia.

\section{2) Del averno de los discursos vacíos al infierno intestino}

La representación de la violencia hacia el cuerpo migrante aparece a través de la imagen del infierno que difiere en las dos obras: instalado en la producción literaria mexicana sobre la literatura de migración, esta violencia aparece de manera incipiente en la literatura chilena, procesando todavía su relación con el migrante del siglo XXI. Al infierno se asocia el fuego, que inicia La fila india y concluye Ciudad berraca.

El Biempensante caracteriza a México como el infierno dantesco del pecador migrante con siete círculos en vez de los nueve de la Commedia. Inventa entonces el nuevo recorrido (85-87) : en el primer círculo, el cuerpo migrante está sujeto el robo y la violación; en el segundo, tiene que 
sobrevivir a la bestia, el tren en el cual se hacina su cuerpo; en el tercero, todo lo pagado para vivir en el viaje es regateado a los pasajeros tanto por los coyotes como por la policía y la Conami ; en el cuarto, el cuerpo migrante se encuentra en la imposibilidad de escapar convirtiéndose en una mercancía desechable ; en el quinto, el cuerpo migrante es incapacitado de viajar por sus propios medios sino será torturado o desechado ; en el sexto, el cuerpo migrante no podrá ser rescatado por nadie ya que nadie, salvo unas ONG sin envergadura, se interesa en su suerte ; en el séptimo, si el cuerpo migrante logra sobrevivir al viaje, nada indica que podrá entrar facilmente a Estados Unidos porque son los mismos coyotes mexicanos que guardan la frontera. Si logra llegar al final del recorrido, el cuerpo migrante entra a otro infierno : "Una vez allá, felicidades. Respira hondo : el horror ya corre por cuenta de los gringos" (87). Aparece también una referencia al averno cuando el periodista Luna cuenta a Irma el relato de una masacre mayor a la de Santa Rita : "Luna volvió a referirme los pormenores de su paseo lunar por el averno. La piel de un cuerpo a medio desenterrar ..." (150). Al hacerlo, recalca la recurrente indiferencia de las autoridades frente a las masacres perpetradas en su territorio.

En Ciudad berraca, las descripciones no son dantescas pero sí se observa el mismo término de averno cuando se refiere a las miradas de los chilenos hacia los "cuerpos libres" migrantes "que contrastaban con ciertas personas de allí, de movimientos apretados como robots viejos y miradas punzantes, como si en sus ojos tuvieran dos porciones de fuego lanzadas por el cañón de un averno intestino para incinerar lo que parecía malo" (9). El infierno todavía no se desata totalmente, está encapsulado en los cuerpos de los chilenos y empieza al final. Las miradas reprimen la acción, la envidia corroe los cuerpos inmóviles. En contraste, el cuerpo del migrante puede moverse, puede bailar, puede sentir. El infierno es intestino pero todos están en el borde del precipicio.

El fuego inicia y termina todo, desnuda la piel, su humo golpea el "cuerpo [que] busca una salida" (27). La prosa de Ortuño se poetiza con la evocación del fuego, como una contemplación fascinada por los daños infligidos: "los ensueños en que el fuego regresa a buscar lo suyo, lo que logramos arrebatar a su imperio: todos son motivos para que la vida posterior a nuestras bodas con él sea sólo sombra y parodia" (28). El fuego se personifica en una mano que arrebata, que lenguetea de manera sensual y abominable el cuerpo. El matrimonio del fuego y del hombre deja el cuerpo del último en la oscuridad pero explicita el lazo intrínseco, indeleble. Como un pirómano, se siente una atracción hacia la hoguera. El fuego tiene poderes sobre el cuerpo, lo purifica en cierta manera, elimina sus rasgos petrificadores. No existe esta descripción en la obra 
de Ramos Bañados. En el incendio, solo se describen los cuerpos achurrascados y una dentadura, vestigio de la desaparición.

\section{3) Materialidad de la escritura migratoria}

Los críticos de la obra de Ortuño apuntan al aspecto testimonial y denunciatorio presente en el texto. Chávez-Flores destaca los informes ficticios de la Conami que compara con los del CNDH (Comisión Nacional de Derechos Humanos) real lo que lo lleva a ver una copresencia de logos y mythos en la obra tal como lo ve también Villanueva. Esta última lo constata en la ausencia de separación entre el discurso oficial (ligado a la historia) y el no oficial (ligado a la ficción) (88). El descentramiento del autor en la narración permite dar una voz a los familiares de las víctimas y da lugar a los testigos (91). El desenmascaramiento en esta obra se lleva a cabo con el relato de las masacres de los migrantes centroamericanos al transitar por México: “Cae la máscara del poderoso, quien se revela con toda su crueldad" (100).

Masiello, al analizar la crisis del mundo contemporáneo con relación a la literatura, piensa en los testimonios que quedan del desastre mismo que se convierten en un "devenir materia" en las palabras del crítico de arte Rodrigo Zúñiga. Lo instantáneo, el presentismo (Hartog) responde a un deseo de rendirse a los ímpetus del presente (499). Recalca la paradoja de la literatura que trabaja con lo que no está, con la imaginación de lo ausente (502). El cuerpo constituye entonces para la crítica un punto intermedio entre la "disminución de la experiencia" planteada por Walter Benjamin y la "repartición de lo sensible" según Jacques Rancière. La literatura al representar los cuerpos devuelve la materialidad de la experiencia (502). Las corpografías presentes en la obra no solo muestran la fijación de rasgos raciales. Muestra sobre todo cómo el cuerpo se escapa de su corsé. En el mundo actual, la apatía del ser humano deja solo "la inmediatez del cuerpo y la incomodidad que el dolor produce" (511). Masiello propone volver al sensorio para entender lo que está pasando, reconocer que el ser humano ha perdido su capacidad de maravillarse o de sufrir. Existe entonces un "cuerpo de la literatura que reclama estas crisis del cuerpo social" (511).

Irma, la burócrate desterrada, exiliada, migrante, de La fila india, muestra la ambivalencia o la doblez del poder pero también pone su cuerpo, su sensorio para romper con la indiferencia del sistema institucional. No queda indiferente frente a la historia de Yein, violada una y otra vez en su paso por México. La acompaña, la escucha, la salva y la pierde finalmente. Tampoco es apática cuando lee o escucha los testimonios de los migrantes sobrevivientes: "No podía leer sin asquearme de lo que oí, antes, con las tripas encogidas, de boca de los sobrevivientes. Leer me 
convencía de que podría sucedernos cualquier atrocidad semejante" (75). Termina huyendo de este mundo hacia Estados Unidos y vuelca su mirada hacia su país y el horror que le provoca "Dos océanos entre nosotras y el señorío de los cerdos" (174). Su experiencia tiene que servir y el relato de los cadáveres tienen que materializarse en un cambio. En el texto de Ramos Bañados, Jean encarna el héroe de la nueva realidad de Antofagasta, un mediador entre dos historias, entre dos traumas, el de la colonia y el de la dictadura. En la última oración de la novela: "Fue entonces cuando Jean, el príncipe de Antofalombia, intentó hacer andar el viejo tanque de Pinochet” (145), reaparece la imagen guerrera pero transferida a una nueva realidad, una nueva posibilidad. Los traumas de México y Chile pueden ser releídos, reinterpretados por el lente del cuerpo migrante reinventado, cuya historia de la sobrevivencia desvía la petrificación.

\section{Conclusión}

Las dos obras materializan una conexión entre el cuerpo racializado del migrante y una lectura de lo político. La descripción de este cuerpo petrificado, estereotipado, maltratado, fragmentado permite a la literatura exponer la crisis del cuerpo social que describe. La racialización a ultranza de su cuerpo, la insistencia en revelar las corpografías estereotipadas también evidencia los disfuncionamientos políticos y sociales de México y Chile. El cuerpo del migrante es el espejo de la crisis de estas sociedades neocoloniales que claramente no han superado el trauma originario de la colonia. En ese sentido, la materialidad del cuerpo migrante en la escritura también es el testimonio de las heridas de los países latinoamericanos que sufren una doble subalternidad. La paradoja del cuerpo del migrante, entre racialización y movilidad, tuerce la apatía, da una oportunidad a la semblanza (Adorno). Cómo si el exceso ya empezase a cobrar una visión más ética. Apátrida, el sujeto migrante puede recuperar su lugar en la historia y el territorio así como adquirir una doble pertenencia a través de la materialidad de la escritura. Foucault expone la guerra de las razas que llega a un Estado racializado basado en variantes biológicomedicales. Mbembé expone la ultranza de la relación guerrera en los cuerpos de los mártires y de los sobrevivientes que pueblan la necropolítica del mundo neoliberal. Fanon, trabajando el mundo colonial y postcolonial, también constata la esencialización del hombre negro tal como Quijano constata la perpetuación de la colonialidad del poder. Sin embargo, críticas como Masiello ven en el cuerpo, la célula, este punto de partida hacia una nueva materialidad de la escritura. La literatura continúa dando una posibilidad de modificar la relación a lo político o al menos de resforzar su 
Dossier. Tatiana Calderón Le Joliff. "El cuerpo racializado del migrante en La fila india de Antonio Ortuño y Ciudad berraca de Rodrigo Ramos Bañados".

función testimonial y perfomática. En la literatura de migración, la escritura de los cuerpos de los migrantes encarnan esta apertura, este salida del shock inútil y la posibilidad de reanudar la diálectica con la historia.

*Este trabajo se enmarca en el proyecto de investigación Fondecyt Regular $n^{\circ} 1151147$, titulado "Historia y memoria en la literatura de fronteras: Butamalón (1996) de E. Labarca, Señales que precederán al fin del mundo (2009) de Y. Herrera, Waiting for the Barbarians (1980) de J.M. Coetzee y Le Rivage des Syrtes (1951) de J. Gracq" (2015-2018)" y ejecutado en la Universidad Adolfo Ibáñez. 


\section{Bibliografía}

Adorno, Theodore W. Teoría estética. Madrid : Akal, 2004.

Arendt, Hannah. Eichmann en Jerusalén. Un estudio sobre la banalidad del mal. Barcelona: Lumen, 2020.

Bhabha, Homi K. "Signos tomados por prodigios". El lugar de la cultura. Buenos Aires :

Manantial, 2007. 131-154.

Cairati, Elsa. "La Fila india de Antonio Ortuño". Altre Modernità: Rivista di studi letterari e culturali 2 (2014): 270-273.

Chávez-Flores, Ian . "Mythos y logos: hacia un análisis de la migración contemporánea en La fila india, de Antonio Ortuño". La Colmena 100 (2018): 35-46.

Damasio, Antonio. Descartes' Error: Emotion, Reason and the Human Brain. Hampshire: Pan Macmillan, 1994.

Dorfman, Ariel. La nana y el iceberg. Barcelona: Seix Barral, 2000. (1999)

Fanon, Frantz. Les damnés de la terre. Paris: Éditions La Découverte/Poche, 2002

Fanon, Frantz. Peau noire, masques blancs. Paris: Seuil, 1952.

Foucault, Michel. "Il faut défendre la société". Cours au collège de France (1975-1976). https://monoskop.org/images/9/99/Foucault_Michel_Il_faut_defendre_la_societe.pdf.

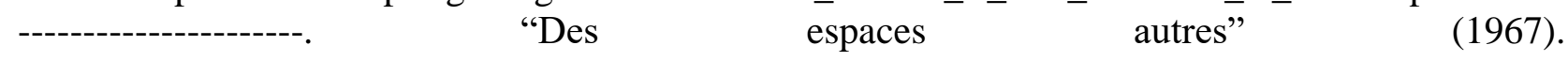

http://www.articule.net/wpcontent/uploads/2008/11/mfoucaultdesespacesautres.pdf.

Hartog, François. Régimes d'historicité. Présentisme et expériences du temps. Paris: Seuil, 2003.

Masiello, Francine. "Cuerpo y catástrofe". Estar en el presente: literatura y nación desde el Bicentenario. Eds. Enrique E. Cortez and Gwen Kirkpatrick. Lima-Berkeley: Latinoamérica Editores, 2012. 492-513.

Mbembé, Achille. Necropolítica. Sobre el gobierno privado indirecto. Buenos Aires: Melusina, 2011.

Moraña, Mabel. Heridas abiertas. Biopolítica y representación en América Latina. Madrid: Iberoamericana Editorial Vervuert, 2014.

Ortuño, Antonio. La fila india. México D.F.: Océano, 2013.

Parra, Marco Antonio de la. La mala memoria: Historia personal de Chile contemporáneo. Santiago de Chile: Planeta, 1997.

Paveau, Marie-Anne \& Zoberman, Pierre. "Corpographèses ou comment on/s'écrit le corps". Itinéraires 1 (2009): 07-19.

Quijano, Aníbal. "Colonialidad del poder y clasificación social”. Cuestiones y horizontes: de la dependencia histórico-estructural a la colonialidad/descolonialidad del poder / Aníbal Quijano; selección a cargo de Danilo Assis Clímaco; con prólogo de Danilo Assis Clímaco. - 1a ed. - Ciudad Autónoma de Buenos Aires: CLACSO, 2014.

Rama, Ángel. La ciudad letrada. Hanover: Ediciones del Norte, 2002.

Ramos Bañados, Rodrigo. Ciudad Berraca. Santiago de Chile: Alfaguara, 2018.

Romero, José Luis. Latinoamérica: las ciudades y las ideas. Madrid: Siglo XXI Editores, 2010.

Salinas Herrera, Liliana. "Desplazamientos : los imaginarios de la travesía de Jean en Ciudad Berraca y Obama de El Metro". Revista de Letras 59-1 (2019): 97-113.

Villanueva Benavides, Idalia Hermelinda. "La deconstrucción del sujeto, del autor y de la estructura narrativa en La Fila india de Antonio Ortuño". Revista Iberoamericana 83-258 (2017): 87-101. 